\title{
Research on the Crisis Management Problems and Countermeasures of Colleges and Universities in Micro Age
}

\author{
Lie Wang \\ College of Food Science, Heilongjiang Bayi Agricultural University, Daqing, China \\ Email: wangerli100@163.com
}

How to cite this paper: Wang, L. (2020) Research on the Crisis Management Problems and Countermeasures of Colleges and Universities in Micro Age. Open Journal of Social Sciences, 8, 244-252. https://doi.org/10.4236/jss.2020.81017

Received: December 31, 2019

Accepted: January 13, 2020

Published: January 16, 2020

Copyright (อ 2020 by author(s) and Scientific Research Publishing Inc. This work is licensed under the Creative Commons Attribution International License (CC BY 4.0).

http://creativecommons.org/licenses/by/4.0/

\begin{abstract}
Taking the new features of crisis events in colleges and universities in the micro-age as the starting point, we focus on exploring the shortcomings of crisis management in colleges and universities, and propose that we should start from five aspects: "establishing new ideas, establishing new mechanisms, adopting new methods, formulating new strategies, and implementing new education". Do a good job of crisis management in colleges and universities in the micro era.
\end{abstract}

\section{Keywords}

Micro-Era, College Crisis Management, Features, Lack of Management, Countermeasures

\section{Introduction}

The "Micro Age" is an era of real-time, interactive and streamlined cultural communication based on digital information, using WeChat, Weibo and other platforms as a communication medium, through graphic, video, audio and other forms. Teachers and students of colleges and universities in the micro era are a group with a relatively high utilization rate of various "micro-communication" platforms, and are one of the main forces in the formation and dissemination of network information. The Statistical Report on the Development of the Internet in China released by the China Internet Network Information Center (CNNIC) shows that as of June 2019, the number of Internet users in China reached 854 million, an increase of 29.84 million compared with the end of 2018. In the micro age, new online media such as Weibo, WeChat, Douyin, Wei Video, and WeChat have gradually penetrated into daily life, which has a major impact on 
the world outlook, outlook on life and values of college students, and gradually changes their learning styles, lifestyle and ways of making friends. Therefore, it brings many new problems and challenges to college crisis management. How to correctly understand and grasp the characteristics of college crisis events in the micro-age and to explore the countermeasures of college crisis management in the micro-age are the key topics that universities need to study.

\section{New Features of University Crisis Events in Micro Age}

\subsection{Many Sources}

In the micro era, since the media has become widespread, everyone controls the "microphone", and can publish all kinds of information on Weibo, WeChat, Douyin and other platforms to interact independently. The operating bodies of new media in universities are also diversified. A survey on campus new media in 2018 showed that the number of self-media public accounts accounted for about $50 \%$; the official school platform exceeded $20 \%$, and student organizations accounted for about $30 \%$. Opinions are expressed in a variety of media and ways, involving complex content and diverse perspectives [1]. The threshold of the micro-communication platform is relatively low, and no one checks it, giving the university public opinion events more opportunities. Due to the unknown and uncontrollable nature, any slight negligence or failure of details in the work of college students in the micro-age may become the source of public opinion. Any teacher or student or alumni in the university can be a trigger of public opinion [2].

\subsection{Fast Propagation Speed}

Traditional media has deadlines, and the speed of public opinion transmission is generally calculated in terms of days and hours. Therefore, public opinion management emphasizes the principle of response within 24 hours. In the micro era, the speed of public opinion transmission is generally calculated in minutes and seconds, and the new media has no deadlines. Information can be released anytime and anywhere. Therefore, the response speed of public opinion in colleges and universities must be greatly improved.

\subsection{Wide Propagation Path}

In the micro era, the propagation path of public opinion events has exhibited diversified characteristics. New media such as Weibo, WeChat, Weishi, Douyin have become the main channels for public opinion. In the spread of public opinion, the combination of new media and traditional media is more likely to form large-scale interactions. Through language, text, pictures, videos and even spoofs, it is easier to cause a large number of retweets and exacerbate the crisis.

\subsection{Upgrade Fermentation Fast}

In the context of the micro-era, the main body of crisis event transmission in 
universities is students and teachers who hide their true identities. Their respective qualities, hobbies, and standpoints are different, and their perceptions of crisis events are also different. Some teachers and students are emotional and emotional about crisis events, lack of rational thinking, and under the lack of media supervision and ethical constraints, they can easily become disseminators of bad information and false information, making events worsening and upgrading. In addition, micro-platform the attitude of opinion leaders towards crisis events will also become an important factor in the rapid fermentation and upgrading of the crisis.

\section{5. "Merge Media" Plays a Big Role}

Traditional media and new media are also likely to form large-scale interactions in the spread of public opinion. Through text, pictures, videos and even spoofs, the public opinion events are spread in a three-dimensional mode, and a simple event is quickly pushed to the forefront.

\section{The Lack of Crisis Management in Colleges and Universities in the Micro Era}

The new features of crisis events in colleges and universities in the micro era have put forward higher requirements for college crisis management and brought new challenges. Crisis management in colleges and universities has not kept pace with the times, and there are still some shortcomings.

\subsection{Lack of Ideas}

The lack of the concept of crisis management in universities is mainly reflected in the lagging of the concept of crisis events in universities, specifically in evading responsibility and unwilling to take responsibility; blocking information, not timely and adequate disclosure of information; insufficient attention, lack of urgency; lack of sensitivity. We cannot be keenly aware of the emergence of crisis events; crisis awareness is not strong, and crisis management is still at the level of remediation, which delays the favorable time for crisis management. Lagging of ideas directly leads to improper crisis management in colleges and universities, and the escalation of events has intensified.

\subsection{Lack of Mechanism}

There are very few universities in China that have established specialized crisis management organizations. Generally, when a crisis event comes, a working group is set up temporarily, and the working group that ends the event is dissolved. Although some effective experiences will also be accumulated during the process of crisis events, it cannot form a long-term mechanism for crisis management and cannot cope with the new situation of university crisis in the micro-era. The lack of "micro" platforms for crisis monitoring in crisis prevention, unable to find the source of the crisis, understand the trend of the crisis, cor- 
rectly identify the characteristics of the problem, determine the trend and trend of the crisis, and ultimately lead to the failure of effective crisis prevention. The lack of rapid response mechanism and network communication mechanism in crisis response leads to poor crisis management effect, and it is easy to cause two or more crises. In the crisis assessment, the lack of content reconstruction using the "micro" platform is not conducive to restoring and making up for the damaged image of colleges and universities, and it is impossible to effectively convert dangers into "opportunities" [3].

\subsection{Lack of Ability}

The research on crisis event processing in Chinese universities started late and is still in the exploratory stage. Crisis handling capabilities are even more incapable of meeting the requirements of the micro-age. The main manifestations are as follows: First, the response speed is too slow, and the generation and appearance of online public opinion information in the micro-age is short. All public opinion information will suddenly turn into a crisis event of online public opinion in some unprepared state, but most universities lack the construction of various working mechanisms such as monitoring and alarming, public opinion guidance, and crisis management in the management of online public opinion. When a crisis occurs, we cannot respond in time. The second is that the attitude of crisis management is not frank and equal. They still like to use traditional methods, do not respond directly to questions, and talk empty words and rhetoric. The third is that the way of crisis management is not flexible enough to make full use of various channels and platforms and form them. Work together to cope with the crisis, without a good grasp of communication skills with the public, unable to gain the understanding and support of the public; Fourth, the lack of public relations capabilities, after the crisis broke out, some managers lacked clear logical thinking, neglected the college public network information, The effective interaction between the crisis event and the actual security maintenance work on campus only adopts cold processing methods such as deleting bad public opinion information, suppressing the impact of crisis events, and avoiding key issues. It cannot effectively form empathy among teachers and students, reducing the risk of network public opinion crisis management effectiveness [4].

\subsection{Lack of Literacy}

Media literacy is an extension of traditional listening, speaking, reading and writing abilities, and it is the ability to interpret and criticize various types of media information. With the rapid rise of new media, the lack of media literacy, especially new media literacy, is very obvious. Some teachers and students are unable to distinguish the difference between "media reality" and "objective reality". They have a high blind dependence on new media and are not rational enough to look at problems. Many college and university crisis incidents occur 
because our students and faculty members lack a rational judgment of the information and show randomness in disseminating the information. They took the lead and proactively exposed the event on the new media, and collectively participated in the comment and forwarding of the event China to further escalate the crisis.

\section{Research on the Crisis Management of Colleges and Universities in the Micro Age}

In 2017, Heilongjiang Bayi Agricultural University student work project construction, I mainly undertake the research of "student safety gridded management model construction" project. This project introduces gridded management ideas in university emergency management, using the network. The characteristics of smooth management information, rapid resource integration, and strong ability to independently adjust internal resources have improved the emergency management mechanism for university emergencies, and enhanced the school's emergency management capacity for emergency management. This study combines the new features of crisis events in colleges and universities in the micro-era and the lack of crisis management in colleges and universities. Based on a large number of readings of relevant literature by experts and scholars and some successful cases of colleges to resolve the crisis, I work as a counselor. With years of experience, I have initially explored countermeasures for crisis management in colleges and universities in the micro era.

\subsection{Set Up New Ideas}

The concept of crisis management in colleges and universities must be kept up to date and updated in accordance with the characteristics of public opinion events in the micro-age. The concepts of responsibility and information disclosure are the most important concepts that universities in the micro-ages need to establish in the management of public opinion. The concept of responsibility is to dare to take responsibility. Once a public opinion event occurs, as long as the university is involved, regardless of whether the responsibility is in the university itself, it should take the initiative to show a willingness to take responsibility and a sympathetic attitude towards the injured, so as to win the public understanding and trust. The concept of information disclosure is that relevant departments should release crisis information openly, truthfully, and in time to prevent the spread of various rumors and bad information [5].

\subsection{Establish a New Mechanism}

Facing the new requirements and new challenges in the management of public opinion in the micro-ages, colleges and universities should restructure the public opinion management mechanism in a targeted manner, and include the "micro-mechanism" as an important component. The first is the public opinion prevention mechanism. Establish a public opinion monitoring mechanism to 
understand the changes in online culture and student netizens' behavior; establish a self-media platform with online discourse channels, such as the official website, official Weibo, official blog, etc; learn how to communicate in the micro age, and interact with students or major stakeholders communication; formulate network behavior norms for college students in the micro-age; establish a good interactive relationship with the public, especially with relevant opinion leaders and important media. The second is the public opinion handling mechanism. Quickly reflect, find the real problem, make quick decisions, curb the growth of the problem; fully consider the emotional factors, consider the changing network culture; pay attention to the voice of the majority of students, their speeches on social media are critical to the success of public opinion processing important; attach importance to the opinions and feelings of opinion leaders; adopt new digital technologies for integrated communication. The third is the public opinion restoration mechanism. Formulate new rules and regulations, standardize new procedures, and how to ensure that the problem does not happen again; through reflection on public opinion events, optimize the internal organization's processing process and organization to respond to public opinion in the micro-age, so as to better use social media platforms for information communication [6].

\subsection{Take a New Approach}

Aiming at the seriousness of the negatives of different media, the methods of timely and effective handling of negative information can be summarized as: reply, sink and dilute. The reply is applied to Weibo, forums, posts, knows, blogs and other media. Through network monitoring, the potential needs of users are found in various social media at the first time, and the corresponding responses are combined with the characteristics of the event itself to directly eliminate and reduce negative impact of information. Sinking is used in media such as forums, posts, and knowing. When negative information is found, positive information is released to balance the positive and negative sounds. After sinking to 5 pages at a time within 2 hours, the purpose of sinking is to reduce the exposure of negative information. Dilution is used in news comment area, video comment area, blog comment area, etc., find negative information, balance positive and negative sounds in the comment area, all in place in 1 hour.

\subsection{Develop a New Strategy}

In the micro-era, colleges and universities should also formulate new strategies in response to public opinion events. The first is accurate judgment. When handling public opinion events, universities must first have an accurate judgment of the event, and then decide whether to respond. The judgment of the university should be based on the nature of the incident and the data provided by real-time monitoring. If it is related to the safety of the life of the net name, or if there is an opinion leader involved in forwarding and commenting, it must respond 
immediately. At the same time, we must set the tone in a timely manner, first cut into the public opinion from the perspective of self-interest, and find the appropriate first place for the accurate setting of the public opinion. Let public opinion develop in accordance with the established tone, so as to achieve the effect of controlling and guiding public opinion. The second is rapid response. The fission effect of communication in the micro age has greatly increased the speed of public opinion response, from the " 24 hours" of the traditional media era to "the golden 4 hours" or even the "golden quarter of an hour". The "first impression effect" plays an important role at this time. The earliest information is announced to take the initiative to master the information, and it is easiest to gain the trust of the audience. When publishing information, we must pay attention to the principle of "flashing facts, cautiously reporting, and re-reporting progress". For complex events, we cannot wait until the full results are announced before publishing them. We must publish them in stages according to the progress to meet the public expectations, reduce the spread of all kinds of rumors. The third is multi-party coordination. For the handling of sudden public opinion incidents, do not be self-defeating, rely on the school's party and government collective leadership, strengthen internal solidarity, clear division of labor within the system, perform their duties, leave no vacuum, and avoid losing sight of each other. At the same time, we must unite our strength, make unified deployment, coordination, and processing, and make a unified voice.

\subsection{Promote New Education}

Aiming at the lack of media literacy, universities should highlight the role of media literacy education and actively develop new media literacy education. Colleges and universities should actively carry out the universal education of new media literacy courses for college students, and can set up online and offline related courses on new media literacy to allow college students to receive more professional new media literacy education. Educational content should conform to the requirements of the development of the times, carry out education and training around media language, media technology, media characteristics, media consumption, and the role of the media in the socialization process, and enhance college students' awareness of new media and the ability to use new media. Identify new media and gradually have the ability to use the new media to develop themselves. In addition, colleges and universities must give play to the subjective initiative of teachers and students to strengthen self-cultivation of new media literacy. First of all, teachers and students in colleges and universities must establish a basic understanding of new media, grasp the characteristics of new media, self-control the time of exposure to new media, and do not rely too much on new media and indulge in the Internet. When using new media, make reasonable arrangements for various needs such as information acquisition, interpersonal communication, entertainment and leisure, scientifically contact and select new media, and improve use efficiency. Secondly, we must establish our own 
critical thinking, do not judge things based on your own preferences, easily draw conclusions, do not trust the so-called "official" statement, be easily brainwashed, think twice before facing new things, and constantly improve your rational discrimination and criticism new media capabilities. Third, we must have a sense of self-discipline when using new media, do not abuse the new media, and enjoy freedom of speech on the premise of complying with social moral and legal standards. Finally, we must learn to use various new media technologies in a balanced manner, obtain media information in a variety of ways, actively use new media to participate in public discussions, and make official decisions, so as to continuously improve our comprehensive ability to control new media [7].

\section{Acknowledgements}

In the micro age, new media such as Weibo, WeChat, Weishi and Douyin have become an indispensable part of the daily communication between teachers and students in universities. These "micro-communication" platforms can easily promote the crisis events in colleges and universities to form online public opinion and rapidly promote the upgrade. Improper handling will affect the harmony and stability of universities. Facing the new features and challenges of crisis events in the micro-era, ideological and political education in universities must closely focus on the goals and tasks of "building people with morality", continuously strengthen the mainstream ideological public opinion in universities, and establish responsibility and information disclosure in crisis management. Concept, build an emergency "micro" mechanism, adopt new processing methods, implement new management strategies, and strengthen the education of teachers and students in the relevant legal system and regulations, so as to achieve the goal of building a civilized and harmonious campus.

\section{Conflicts of Interest}

The author declares no conflicts of interest regarding the publication of this paper.

\section{References}

[1] Xu, J. (2019) Guidance Mechanism and Practice Path of University Public Opinions in the "Micro-Era". News Enthusiasts, 8, 214-216.

[2] Wu, Z.M. (2019) Research on University Crisis Management since the Media Age. Reading and Writing, Beijing, 200-202.

[3] Jiang, Q.Y. (2013) Probe into University Crisis Management in Micro Age. Journal of Huaibei Normal University, 5, 99-101.

[4] Nu, Q. (2018) Research on the Crisis Management Mechanism of Internet Public Opinion in Colleges and Universities under the Background of Media. Journal of Hubei Correspondence University, 31, 403-405.

[5] Zhang, L.J. (2018) Research on Crisis Management Problems and Countermeasures of Independent Colleges in the Era of "Micro-Communication". New Media Research, 7, 122-124. 
[6] Chen, X.M. (2013) Analysis of University Crisis Management Strategy in the Micro-Era. Journal of Xi' an University of Arts and Science, 3, 22-24.

[7] Chen, H.F. and Qin, Y. (2019) Investigation and Analysis of the New Media Literacy Status of College Students after the 00s-Taking Nanjing Xiaozhuang University as an Example. Media Forum, 2, 95-97. 